\title{
Taxonomy of the Species Pseudomonas odorans
}

\author{
By I. MÁLEK, MILUŠ RADOCHOVÁ AND O. LYSENKO \\ Microbiological Institute, Czechoslovak Academy of Sciences, Prague, Czechoslovakia
}

(Received 12 July 1963)

\section{SUMMARY}

Several strains of the formerly described micro-organism then named Pseudomonas odorans Málek \& Kazdová-Kožišková were examined. It was found that this organism belongs to the genus Alcaligenes. A re-descripof the species and a discussion of its taxonomic position is given.

\section{INTRODUCTION}

During the Second World War several clinical microbiologists isolated from their diagnostic material a micro-organism which was readily recognized by its odour reminding one of valerian tincture. The micro-organism was isolated from stools, from urine and in one case from pus. Its identification was difficult at that time on account of the lack of available literature and material for comparison so that it was not until 1946 that a description was published (Málek \& Kazdová-Kożišková, 1946) and it was given the name Pseudomonas odorans. Inasmuch as its description was published in Czech in a non-microbiological journal, it did not become generally known and the name cannot be found in Bergey's Manual $(1948,1957)$ or in any other compendium. Since the present authors encountered this organism on several occasions, not only in clinical material but also in collected insects, indicating its rather wide ecological occurrence, they deem it proper to revise and supplement the original description.

\section{METHODS}

Strains. A total of five strains was examined. Two (Ссев 554, 553) were obtained from the collection of the Institute of Epidemiology and Microbiology in Prague where they are registered as Pseudomonas odorans 14/45 and 15/47. They were deposited in 1945 and 1947, respectively. The strain designated CCEB 015 was isolated in 1954 from the larvae of the midge Chironomus plumosus collected at the Vltava river in Prague and was originally identified as an atypical Alcaligenes viscosus var. dissimilis Long \& Hammer (see Catalogue of CCEB 1958, 1963). The strains designated $\mathrm{N} 28$ and $\mathrm{N} 46$ were isolated in 1960 from the larvae of the nematode Neoplectana carpocapsae Weiser kept in this laboratory.

\section{Diagnostic methods}

Morphological properties. The morphology of organisms was investigated in a 1-day culture grown on meat peptone agar and broth. Flagella were stained by the silver-plating method of Rhodes (1958); capsules by negative staining with nigrosine. The morphology of colonies was investigated with 1-day cultures grown on meat peptone agar, Endo agar and blood agar. 
Biochemical and cultivation properties. Unless stated otherwise all the tests were made at $28^{\circ}$. The formation of acid from carbohydrates was investigated in peptone water $(\%, \mathrm{w} / \mathrm{v} ;$ Bacto peptone $1 \cdot 0 ; \mathrm{NaCl} 0 \cdot 5 ; \mathrm{pH} 7 \cdot 2)$ containing $1 \%(\mathrm{w} / \mathrm{v})$ of the appropriate carbohydrate, with bromothymol blue as $\mathrm{pH}$ indicator. The ability of an organism to utilize carbohydrate as the sole source of carbon was studied in the defined medium of Seleen \& Stark (1943); the utilization of organic acids was tested in the Koser base medium with phenol red and one of the following acids : $(\%, \mathrm{w} / \mathrm{v})$ citric $1 \cdot 0$; malonic $1 \cdot 0$; benzoic $0 \cdot 3$; formic $0 \cdot 1$. 'Sugar' and organic acid solutions were sterilized by filtration. The cultures were observed for 4 weeks. Oxidation of gluconate was tested in the medium of Sneath (1956) after incubation for 5 days, the formation of indole in tryptone broth by the Kovacs method after incubation for 5 days, hydrogen sulphide by the microtest of Rhodes (1959), urease in Christensen medium within 7 days. For acetoin (Voges-Proskauer) and for the methyl red test the following medium was used: $(\%, w / v)$ Bacto-peptone 0.5; $\mathrm{K}_{2} \mathrm{HPO}_{4}, 0 \cdot 5$; glucose, $\mathbf{0 . 2 5}$ or galactose, $0 \cdot 25$; initial $\mathrm{pH} \mathbf{7 \cdot 0}$. The results of both tests were read during 14 days and acetoin detected according to Barritt. For the phenylalanine test and for the potassium cyanide test the modifications described in the Report (1958) were used. The reduction of nitrates was investigated in $\mathrm{KNO}_{3}$ broth with Durham tubes after incubation for 5 days, using the Griess-Ilosvay reagent and checking with zinc dust for false negatives. Litmus milk was examined over 14 days; liquefaction of gelatin in a broth medium over 6 weeks; formation of arginine dihydrolase according to Moeller over 7 days; the iodoacetate test according to Lysenko (1961); starch hydrolysis was detected by Lugol's solution after incubation for 5 days cultivation on meat peptone agar with $0.2 \%(\mathrm{w} / \mathrm{v})$ starch. The formation of catalase was detected by adding two drops of strong hydrogen peroxide solution to 1-day broth cultures, the formation of oxidase according to Kovacs (1956). The ability of organisms to grow at $42^{\circ}$ and at $5^{\circ}$ was tested in broth cultures incubated in water baths. The sensitivity to antibiotics was determined by the tablets method routinely used in diagnostic laboratories on $2.0 \%(v / v)$ blood agar, the only exception being that the drop method was used for tesing polymyxin. For determining the resistance to sodium chloride we used a broth culture, for determining the resistance toward the pteridine derivative 0/129 (2,4-diamino6,7-di-isopropylpteridine) the method of Rhodes (1959) was used.

\section{Serological methods}

Immune sera for the strains investigated were obtained by immunizing rabbits with a mixed vaccine containing $10^{8}$ organisms $/$ ml. made up with 1 part live 6-8 hr. broth culture, +1 part of the same broth culture after boiling for $100 \mathrm{~min}+2$ parts of a lipid adjuvant. The first dose $(1 \mathrm{ml}$.) was injected intramuscularly below the shoulder-blade, the subsequent three doses were given intraperitoneally without the lipid adjuvant at 3-day intervals. Slide agglutination and test-tube agglutination with live antigens, with both $\mathrm{H}$ - and $\mathrm{O}$-antigens and also cross-absorption tests were carried out. For the sake of comparison slide agglutination was also carried out with Pseudomonas aeruginosa sera obtained from Dr Tomasoffova. 


\section{Pathogenicity}

Mice, rats, guinea-pigs, hamsters and rabbits were used. The animals were injected subcutaneously, intraperitoneally and intramuscularly with $0 \cdot 2,0 \cdot 6$ and $1.0 \mathrm{ml}$. broth culture containing $10^{9}$ organisms $/ \mathrm{ml}$. Similar injections of dead organisms and filtrates of broth cultures were given.

\section{Table 1. Biochemical and cultivation properties of the strains examined}

$\begin{array}{lccccc} & & & & & \text { Pseudomonas odorans } \\ \text { Odour } & 554 & \mathrm{~N} 28 & \mathrm{~N} 46 & 015 & \text { (original description) }\end{array}$

No acid in broth from glucose, galactose, maltose, lactose, sucrose, mannitol, glycerol, salicin, dulcitol, starch in strains $554, \mathrm{~N} 28, \mathrm{~N} 46,015$.

No acid in broth from lactose, sucrose, mannitol, glycerol, salicin (others not tested) in P. odorans

Utilization as a $\mathrm{C}$ source:

$\begin{array}{lcccc}\text { Citrate } & + & + & - & + \\ \text { Malonate } & + & + & - & \times \\ \text { Benzoate } & \times & - & - & \times \\ \text { Formate } & (+) & \times & - & - \\ \text { Medium without C source } & - & \times & - & -\end{array}$

The following $\mathrm{C}$ sources were not utilized by any strain: glucose, galactose, lactose, mannitol, glycerol, mannose, inositol, xylose

\begin{tabular}{|c|c|c|c|c|c|}
\hline Oxidation of gluconate & - & - & - & - & \\
\hline Indole formation & - & - & - & - & - \\
\hline Voges-Proskauer test & - & - & - & - & - \\
\hline Methyl red test & - & - & - & - & - \\
\hline \multicolumn{6}{|l|}{ Reduction of $\mathrm{NO}_{3}$} \\
\hline & + & - & - & - & - \\
\hline To $\mathrm{N}_{2}$ & - & - & - & - & \\
\hline Ammonia from peptone & + & + & + & $x$ & + \\
\hline Formation of $\mathrm{H}_{2} \mathrm{~S}$ & - & - & - & - & + \\
\hline Urease & - & - & + & - & \\
\hline Gelatin hydrolysis & + & - & + & - & \\
\hline Litmus milk & A & $\mathbf{A}$ & $\mathbf{R P}$ & 0 & $\mathbf{P}$ \\
\hline Phenylalanine & - & - & - & - & \\
\hline Starch & $(+)$ & - & - & - & \\
\hline Growth with $5.0 \% \mathrm{NaCl}$ & + & + & + & + & + \\
\hline Growth with $6.5 \% \mathrm{NaCl}$ & + & + & + & + & \\
\hline Sensitivity to pteridine $0 / 129$ & - & - & - & - & \\
\hline $\begin{array}{l}\text { Growth in presence of } \\
\text { iodoacetate }\end{array}$ & $x$ & $x$ & $\times$ & $\times$ & \\
\hline Growth in KCN & - & - & - & - & \\
\hline Arginine dihydrolase & - & - & $(+)$ & $x$ & \\
\hline Catalase & + & + & + & + & + \\
\hline Oxidase & - & + & + & + & \\
\hline Growth at $42^{\circ}$ & - & - & + & - & At $40^{\circ}$ \\
\hline Growth at $5^{\circ}$ & $x$ & $x$ & - & $x$ & \\
\hline \multicolumn{6}{|l|}{ Sensitivity to } \\
\hline Penicillin (10 i.u.) & - & - & - & - & \\
\hline Streptomycin $(20 \mu \mathrm{g})$. & - & $(+)$ & - & $(+)$ & \\
\hline Chloramphenicol (20 $\mu \mathrm{g})$. & - & - & $(-)$ & $x$ & \\
\hline Aureomycin $(50 \mu \mathrm{g})$. & - & - & - & - & \\
\hline Terramycin $(50 \mu \mathrm{g})$. & - & - & - & - & \\
\hline Polymyxin $(100 \mu \mathrm{g})$. & $x$ & - & - & - & \\
\hline
\end{tabular}

+ positive; $(+)$ late positive; $\times$ very weak or uncertain; - negative; A alkaline; P peptonization; $R$ reduction; 0 unchanged. 


\section{RESULTS}

As it was found that the strain СCEв 553 was actually Pseudomonas fluorescens (according to the definition proposed by Lysenko, 1961), did not correspond to the original description of $\boldsymbol{P}$. odorans and differed from the remaining strains, we shall not deal with it in this paper. The remaining four strains were Gram-negative nonspore forming rods, $0.5-0.8$ by $0.8-1.2 \mu$ in size, motile, forming peritrichous flagella (Pl. 1, fig. 1, 2, 3), non-capsulated. They occurred singly, in pairs or irregularly.

On agar medium the strains 554 and 015 formed flat, slightly spreading or rounded, slightly convex, translucent colonies. On meat peptone agar and Endo agar the diameter of the colonies was 1-2 mm., on blood agar 5-6 mm.; with the exception of the strain $\mathrm{N} \mathbf{2 8}$ which even there formed small colonies. On Endo agar young cultures of strains 554 and 015 had an odour typical of jasmine ranging to strawberries, in older cultures an odour of ammonia prevailed. With strain $\mathrm{N} 46$ the S-R dissociation of colonies was observed.

On agar slopes strains $\mathrm{N} 46$ and N 28 were characterized by highly filamentous growth; strains 554 and 015 formed a thin spread growth.

The biochemical and cultural properties are shown in Table 1. For comparison the corresponding properties of Pseudomonas odorans according to the original description are also listed.

Antigens. The four strains differed antigenically. An antigenic relationship was found for $\mathrm{N} 28,015$ and $\mathrm{N} 46$ with live antigens, though the titre never reached 1/80. The $\mathrm{O}$-antigenic relationship was more pronounced; all strains possessed some antigenic components in common with $N 46$ (titre $1 / 80$ to 1/160) and $N 28$ appeared to be related to 554 and $N 46$ (titre $1 / 160$ to $1 / 320$ ). The relationship between the $\mathrm{H}$-antigens was less pronounced; titres exceeding $1 / 20$ were found only between $\mathrm{N} 28$ and $554(1 / 40)$ and between 015 and $\mathrm{N} 28$ (1/80).

The strains did not agglutinate with serotypes of Pseudomonas aeruginosa, with the exception of $\mathrm{N} 28$ which produced a very weak reaction with the serotype b 112 .

Strains 554 and N 28 were very weakly pathogenic for mice in which, within 24-48 hr. of intraperitoneal injection of a large dose of organism, a slight to heavy peritonitis appeared, and blood, spleen and intestine yielded pure cultures of the injected organisms. Strains 015 and $\mathrm{N} 46$ were not pathogenic and the filtrates from all the strains did not appear to be toxic.

\section{DISCUSSION}

Comparing these strains with the original description of Pseudomonas odorans (see Table 1) it can be seen that the strains CCEB 554 and 015 and those designated $\mathrm{N} 28$ and $\mathrm{N} 46$ correspond in most of their properties with the original description of $\boldsymbol{P}$. odorans. By virtue of its typical odour and its physiological properties the strain 554 agrees best with the original description and it was deposited in the collection as the authentic type culture. It can be so designated although it differs from the original description in its ability to reduce nitrate, its inability to produce hydrogen sulphide and in its reactions in litmus milk. These discrepancies may be explained by differences in the methods used and perhaps by the long laboratory maintenance.

Strain N 46 shows the greatest number of tests in exact agreement with the limited 
number of characters in the original description; in the present work many more characters were determined and in these all the strains were not alike. The serological relations were apparent and two strains showed similar degrees of pathogenicity. The differences found may be considered to indicate the range of variability of characters that is permissible in this species. The designation of a type strain establishes the pattern for the species and the peculiar odour of strain 554 becomes one of the characters. This fruity or valerian odour might suggest that the bacterium could be classified as Pseudomonas fragi (Eichholz) Huss, strains of which have a similar odour (Castell, Greenough \& Dale, 1959) when it is grown under appropriate conditions (Pereira \& Morgan, 1957; Collins, 1955; Castell \& Greenough, 1959). The differences between $P$. fragi and the strains investigated are mainly in the shape and disposition of flagella, and in the mode of carbohydrate utilization. Strains of $\boldsymbol{P}$. fragi might, if incompletely characterized, be confused with our strains. Even though the value of the arrangement of flagella as a taxonomic feature is debatable, it is still used as a characteristic for differentiation of Pseudomonas from other Gram-negative bacteria. In this respect the bacterium which is being described here cannot be regarded as a member of the genus Pseudomonas as newly defined by Rhodes (1959) or Lysenko (1961).

According to the present ideas on the taxonomy of Gram-negative rods this bacterium might belong to the genera Achromobacter, Flavobacterium or Alcaligenes. The present taxonomy of the genus Achromobacter is very confused, the older scheme presented in Bergey's Manual (1957) is inadequate and this is true also for the genus Flavobacterium. Nevertheless, there are some differences between these genera and our organism. Achromobacter species are non-motile bacteria, which can utilize some carbohydrates; with this vague description the genus consists of heterogeneous groups of bacteria (compare Cowan \& Steel, 1961), which cannot be listed in other related genera. Flavobacterium species are Gram-negative, non-flagellate or peritrichously flagellate bacteria, which form a yellow pigment. Our organism does not possess any of these combinations of characters. Therefore we feel that the best solution would be to place our organism in the genus Alcaligenes, even though the species within this genus are also ill-defined. Most papers dealing with the taxonomy of Alcaligenes define only one species, i.e. A. faecalis, and do not recognize any other species (e.g. Sarkar, Choudhury \& Tribedi, 1959; Moore \& Pickett, 1960; Steel, 1961; Cowan \& Steel, 1961). We consider that the species Pseudomonas odorans should be removed from Pseudomonas and placed in the genus Alcaligenes with which it corresponds by its failure to attack carbohydrates and by its peritrichous flagellation.

Within the genus Alcaligenes several species have been described, but there is no evidence whether they should be regarded as distinct species or as different forms of a single species. This is because neither type species have been designated nor comprehensive study of the whole genus made. Therefore we believe it will be useful to re-describe our organism as a distinct species of this genus. The other possibility of creating a synonym is not advisable from the practical standpoint because this would be possible only if the other species were well defined or if the whole revision of the genus were done.

In view of the matter discussed above we consider it justifiable to rename the organism Alcaligenes odorans (Málek \& Kazdová-Kožišková, 1946) comb. nov. and 
newly to define it by a supplemented description which is based on the authentic type culture.

Alcaligenes odorans (Málek \& Kazdová-Koźišková, 1946) comb. nov. Synonym: Pseudomonas odorans, Málek \& Kazdová-Kožišková, 1946). (Odorans, from the Latin odor-odour, odorans-producing odour.)

Morphology of organism: Gram-negative rods, $0.5-0.8$ by $0.8-1 \cdot 2 \mu$, occurring in pairs or irregularly, motile, forming peritrichous flagella; non-capsulated; spores not formed.

Colony morphology. (a) Meat peptone agar $\left(28^{\circ}, 2\right.$ days): spreading, flat, with irregular edges; some strains form convex, round colonies with straight edges; translucent and sometimes slightly yellowish, 1-2 mm. in diameter. (b) Endo agar: colonies analogous to those on meat peptone agar. $(c)$ Blood agar: similar but larger (5-6 mm.); without haemolytic zone. (d) Agar slope: good growth, flat or elevated, filamentous or spreading; slightly yellow in older cultures.

Biochemical and cultural features. In peptone medium acid not produced from glucose, galactose, maltose, lactose, sucrose, mannitol, glycerol, salicin, dulcitol or starch. Galactose, lactose, mannitol, glycerol, mannose, inositol, xylose not utilized as $\mathrm{C}$ source. Weak and limited growth in glucose.

As C source: citrate, malonate and formate used; benzoate utilized poorly or irregularly.

Gluconate not oxidized. Indole, acetoin and hydrogen sulphide not formed. The methyl red test and phenylalanine test are negative. Starch not hydrolysed, or very poorly. The KCN test negative. In a medium with iodoacetate growth rather slight. Arginine dihydrolase not produced, or only very poorly and with a lag.

Nitrate reduced by only some of the strains; no gaseous nitrogen produced. Ammonia formed from peptone, gelatine liquefied irregularly. Litmus milk made alkaline and peptonized and litmus reduced.

Grows in broth $+6 \cdot 6 \% \mathrm{NaCl}$; not sensitive to the pteridine derivative 0/129.

Grows aerobically; forms catalase; most strains form oxidase.

Growth in the range from $5^{\circ}$ to $37^{\circ}$; strains growing at $42^{\circ}$ do not grow at $5^{\circ}$.

Insensitive to penicillin, aureomycin, terramycin, polymyxin; slight and irregular sensitivity to streptomycin and chloramphenicol.

Serological propertie sand pathogenicity. Strains are serologically heterogeneous, some weakly pathogenic for mice on intraperitoneal injection, producing symptoms of enteritis.

Characteristic properties. (a) Inability to utilize carbohydrate; $(b)$ peritrichous flagella; $(c)$ characteristic odour of young cultures.

The species Alcaligenes odorans was originally isolated from human stools, where it occurs frequently; more rarely from urine and very rarely from the pus through infection near the gastrointestinal tract. Also it occurs in water and in the entomophagous larvae of nematodes.

The strain ссев 554 (Culture Collection of Entomogenous Bacteria, Dept. of Insect Pathology, Prague, Czechoslovakia) is the authentic type culture. 

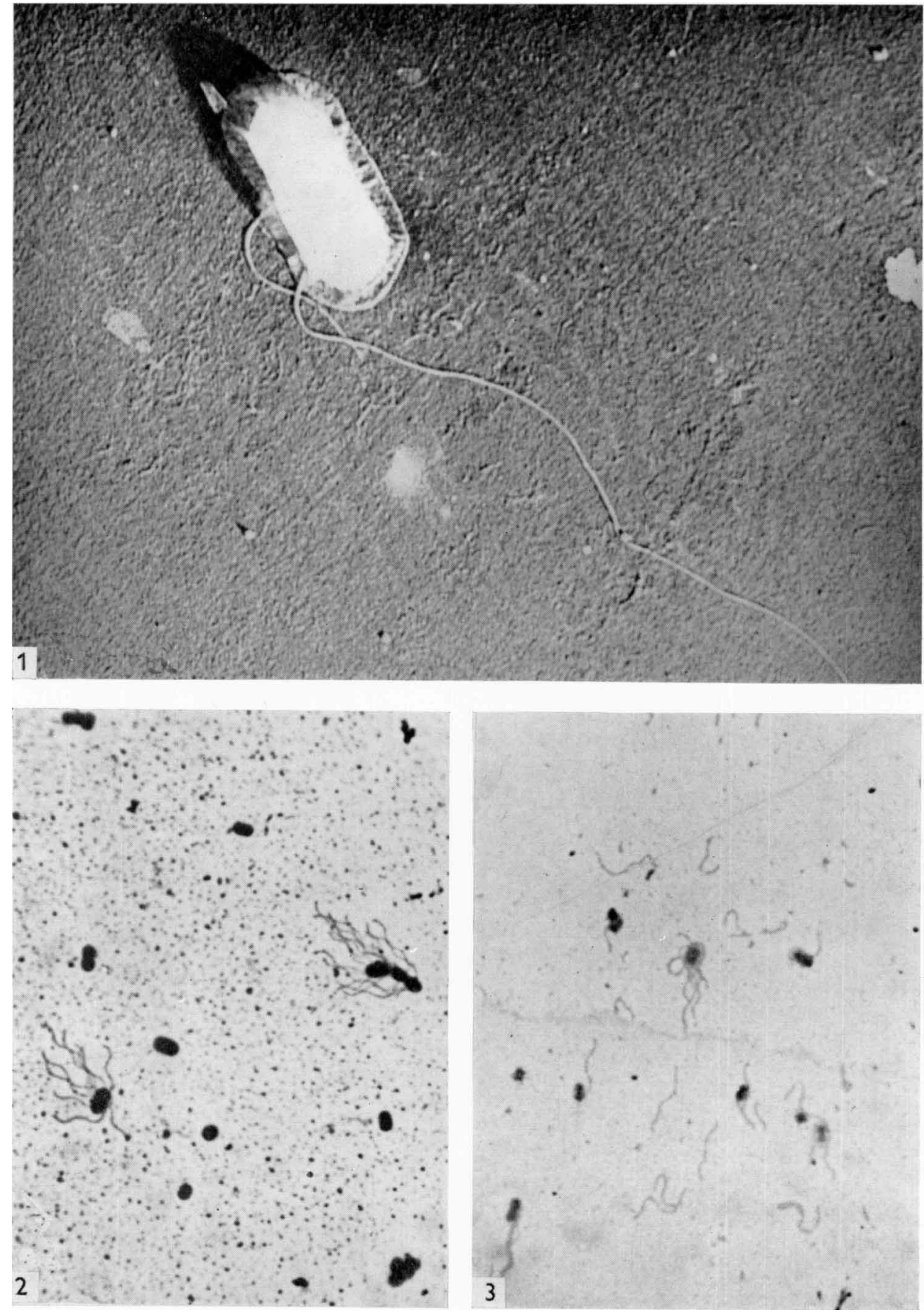


\section{REFERENCES}

Bergey's Manual of Determinative Bacteriology (1948), 6th ed.; (1957), 7th ed. Baltimore: Williams and Wilkins Co.

Castell, C. H. \& Greenough, M. F. (1959). The action of Pseudomonas on fish muscle: 4. Relation between substrate composition and the development of odours by Pseudomonas fragi. J. Fish Res. Bd Canada, 16, 21.

Castell, C. H., Greenough, M. F. \& Dale, J. (1959). The action of Pseudomonas on fish muscle: 3. Identification of organisms producing fruity and oniony odours. J. Fish. Res. Bd Canada, 16, 13.

Collins, E. B. (1955). Factors involved in the control of gelatinous curd defects of cottage cheese. I. Storage temperature and pH. J. Milk Tech. 18, 169.

Cowan, S. T. \& STEEL, K. J. (1961). Diagnostic tables for the common medical bacteria. J. Hyg., Camb. 59, 357.

Catalogue of $\mathrm{CCEB}$. Culture collection of entomogenous bacteria. Catalogue of cultures, 1958, 1st ed.; 1960, 2nd ed.; 1963, 3rd ed. Prague: Inst. of Biology, Czechoslovak Academy of Science.

Kovacs, N. (1956). Identification of Pseudomonas pyocyanea by the oxidase reaction. Nature, Lond. 178, 4535.

Lysenko, O. (1961). Pseudomonas. An attempt at a general classification. J. gen. Microbiol. 25, 379.

Málek, I. \& Kazdová-KożıšKová, V. (1946). Pseudomonas odorans n.sp., novy mikrob z diagnostickeho materialu. Sborn. lekarsky, 47, 189.

Moone, H. B. \& Picket, M. J. (1960). Organisms resembling Alcaligenes faecalis. Canad. J. Microbiol. 6, 43.

Pereira, J. N. \& Morgan, M. E. (1957). Nutrition and physiology of Pseudomonas fragi. J. Bact. 74, 710 .

Report of the Enterobacteriaceae Subcommittee of the Nomenclature Committee of the International Association of Microbiological Societies (1958). Int. Bull. Bact. Nom. Tax. 8, 25.

Rhodes, M. E. (1958). The cytology of Pseudomonas spp. as revealed by silver-plating staining method. J. gen. Microbiol. 18, 639.

Rhodes, M. E. (1959). The characterization of Pseudomonas fluorescens. J. gen. Microbiol. 21, 221.

Sarkar, J. K., Choudhury, B. \& Tribedi, B. P. (1959). Alcaligenes faecalis-its systematic study. Indian J. med. Res. 47, 1.

Seleen, W. A. \& Stark, C. N. (1943). Some characteristics of green fluorescent pigmentproducing bacteria. J. Bact. 46, 491.

SNEATH, P. H. A. (1956). Cultural and biochemical characteristics of the genus Chromobacterium. J. gen. Microbiol. 15, 71 .

STEEL, K. J. (1961). The oxidase reaction as a taxonomic tool. J. gen. Microbiol. 25, 297.

\section{EXPLANATION OF PLATE}

Fig. 1. Alcaligenes odorans, strain cCEB 015. One-day culture. AuPd shadowing. $\times 21,000$. (Photography: Králík).

Fig. 2. Alcaligenes odorans, strain $\mathrm{N} 28$. Leifson stain. $\times 1,600$.

Fig. 3. Alcaligenes odorans, strain ссев 554. Leifson stain. $\times 1,600$. 